\title{
Tourism enterprises in Korca region and their sustainability
}

\author{
Alda GASPARI ${ }^{1}$ (phd candidate)
}

\begin{abstract}
Tourism is considered as one of the economic sectors with the greatest potential to make a positive contribution in achieving sustainable development (UNCED, 1992). Sustainable tourism has become an increasingly popular field of research. There are a wide range of albanian tourism enterprises involved in the tourism industry. The informal nature of tourism enterprises can make it very difficult to spread awareness on sustainable policies, practices and to measure moves towards more sustainable performance. This paper addresses the concept of sustainable development in tourism and examines the degree to which tourism enterprises in Korca region are aware of the broad concept of sustainable tourism. The aim is to determine attitudes of tourism enterprises toward sustainability and understanding the influences on the adoption of sustainability practices, including motivators and barriers .The main findings stresses "a lack of a general awareness about sustainability issues within albanian tourism enterprises. Also as dominant barriers identified were lack of available money to invest, other business priorities,lack of incentive programs. A better understanding of tourism enterprise attributes, barriers, and responses is critical if we are to extend the theoretical concepts that underpin sustainable tourism development and to enhance sustainability in practice.
\end{abstract}

Keywords: sustainability , albanian tourism enterprises,sustainable tourism practices, motivators, barriers.

\section{Introduction}

According to the UNWTO,WT'TC and OECD, tourism is one of the most important and influential economic sectors of the 21 st century. It is a very significant contributor to economic growth, by creating employment and income generation (Zarabi and Parikhany, 2010 ). Tourism sector is directly responsible for about 5\% of the world's GDP. Among decades the demand for tourism has continued to grow. This is clearly seen in the following graphic.

Despite the positive impacts and the growing numbers of international arrivals ,tourism development transforms its destination, usually with many negative outcomes (Cohen, 1978).Tourism exerts considerable pressure on resources and the natural environment,so promotion of sustainable tourism is a necessity. The past years of tourism development have contributed in lot of examples of unsustainable development and the general conclusion has been that" appropriate policy and its implementation" are what are needed to make tourism more sustainable (Asher, 1984, Edgell, 1999). 


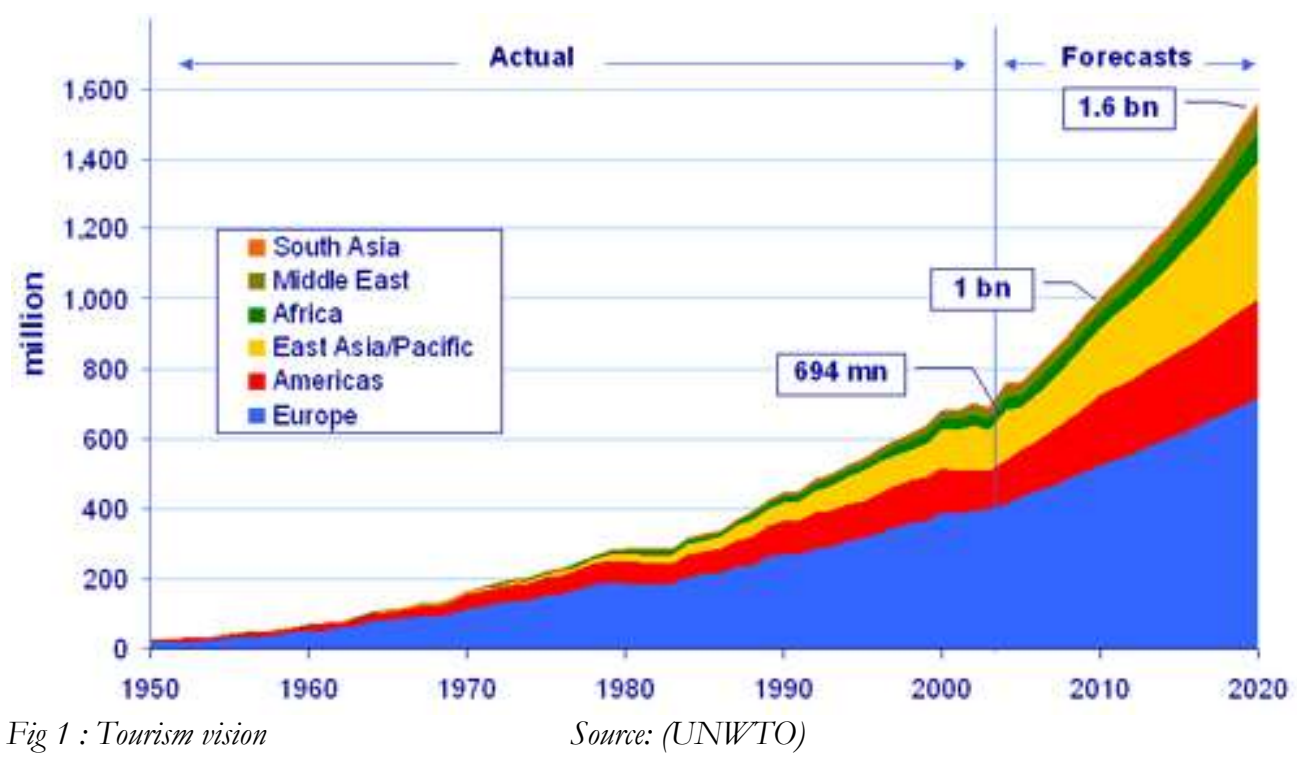

As today's situation might not be perfect yet, tourism businesses are confronted with the question how to bridge and close this gap of the current realities to the sustainable status. The contribution of tourism businesses in the sustainability of the tourist product is considered crucial because sustainable businesses lead to sustainable destinations which in turn lead to successful businesses (Marin Jafari,2002).

The existing literature has various possible definitions of sustainability and related concepts, therefore the aim of the paper is to identify the perception of the tourism businesses in Korca region, about it. This paper contributes to the growing body of literature on sustainability.

Purpose of the Study and Formulation of the Research Questions

In particular the following research questions are :

Do the tourism businesses know about the concept of sustainability?

Are sustainable tourism practices the future for the tourism businesses in Albania?

\section{Tourism development impacts}

Above is mentioned that tourism development transforms its destination, usually with many negative outcomes. One of the differences between tourism and other sectors of the economy is that environmental degradation has a negative impact on the development of the sector itself. The past years of tourism development have contributed many examples of unsustainable development. Before that we begin with the concept of sustainability it is necessary to stop and to classify the impacts of tourism development which are as follows:

Positive economic impacts of tourism development 
Stimulates local production contributing to household incomes and standard of living Generates investment in new businesses, growth of local businesses and business profits Increases employment opportunities

Generates foreign exchange earnings for national economy

Improves development and infrastructure spending in areas such as water, sewerage systems, roads, electricity, telephone, information technology and public transport networks

Offers additional livelihood opportunities for local communities

Locally owned small enterprise development facilitates diversification of the local economy

Self-financing mechanism for natural and heritage attractions and so serve as tool for environmental preservation

Provides economic support for preservation of local culture

Negative economic impacts of tourism development

Increases prices and shortages of goods and services

Increases price of land and housing beyond local affordability

Increases demands on public services and facilities

Increases cost of living

Decline of other industries as resources flow into tourism industry

Higher levels of public debt and/or higher taxes to pay for increased infrastructure and services

Can lead to reduced public expenditure on essential community services

Local employment can be low-level or unskilled, seasonal, low-wage, part-time with little opportunity for advancement.

Positive environmental impacts

Foster conservation and preservation of natural resources

Encourage community revitalisation

Raise revenues for establishing administrative and planning controls to maintain quality of environment

Negative environmental impacts

Has a substantial carbon footprint with contribution to global warming

Adverse effects on water quantity, quality and use, air quality

Waste production, degraded quality of natural sites

Habitat destruction

Positive social impacts

Can lead to removal of social or national prejudices

Can promote better understanding and positive social change

Can play a supportive force for peace

Improves quality of life of locals 
Increases availability of recreation facilities/opportunities

Negative social impacts

Increased prostitution, drug taking and crime

Seasonal nature of tourism promotes immigrant workforce and attendant social problems

Competition and conflict between tourists and residents for available services, facilities and recreational opportunities

Visitor behaviour may be perceived to be 'intrusive' by locals

Positive cultural impacts

Promotes cultural exchange

Facilitates meeting visitors (an educational experience)

Preserves cultural identity of host population

Increases demand for historical and cultural exhibits

Leads to the preservation and revitalisation of local ethnic and cultural identity such as cuisine, music, dance, dress, handicrafts, art and suchlike

Negative cultural impacts

Standardisation.

Loss of authenticity

Cultural deterioration

Multiple challenges arising from tourism development emphasize the promotion of integrated sustainable tourism model. If space is left to the degradation, a tourist destination will not be attractive anymore, therefore the region will lose an important source of incomes. On this basis the concept of sustainability should be considered on the business level through the examination of three principles: economy, society, and environment where the three components" social, environmental, and economic" should not be seen as competing with one another but rather as complementary and even, when handled well, making each other stronger over time .Achieving a balance between economic,social and environment is very important for long term sustainability.

\section{Sustainable tourism development -Literature review}

Sustainability is an increasingly important issue in the tourism industry. The growing concern for environment, resources, social equity in the 1980s led to the emergence of the sustainable development concept. Sustainability development and the application of its principles to tourism are more important now than ever. Sustainability is shown to be a dynamic process of change, rather than a static goal to be achieved. The existing literature about sustainability allows various interpretations of the term. The concept is malleable and can be shaped to fit a spectrum of world views" (Hunter, 1997).The understanding can range from extreme environmental conservation to the extreme environmental exploitation, when the growth of the economy outweighs environmental concerns. Hunter (1997) concluded therefore, that different 
circumstances call for different interpretations of sustainable tourism. The origins of the most widely used sustainability definition traces its roots back to the 'UN report on Environment and Development' published in 1987. This report defines sustainability as: "Meeting the needs of the present without compromising the ability of future generations to meet their own needs".

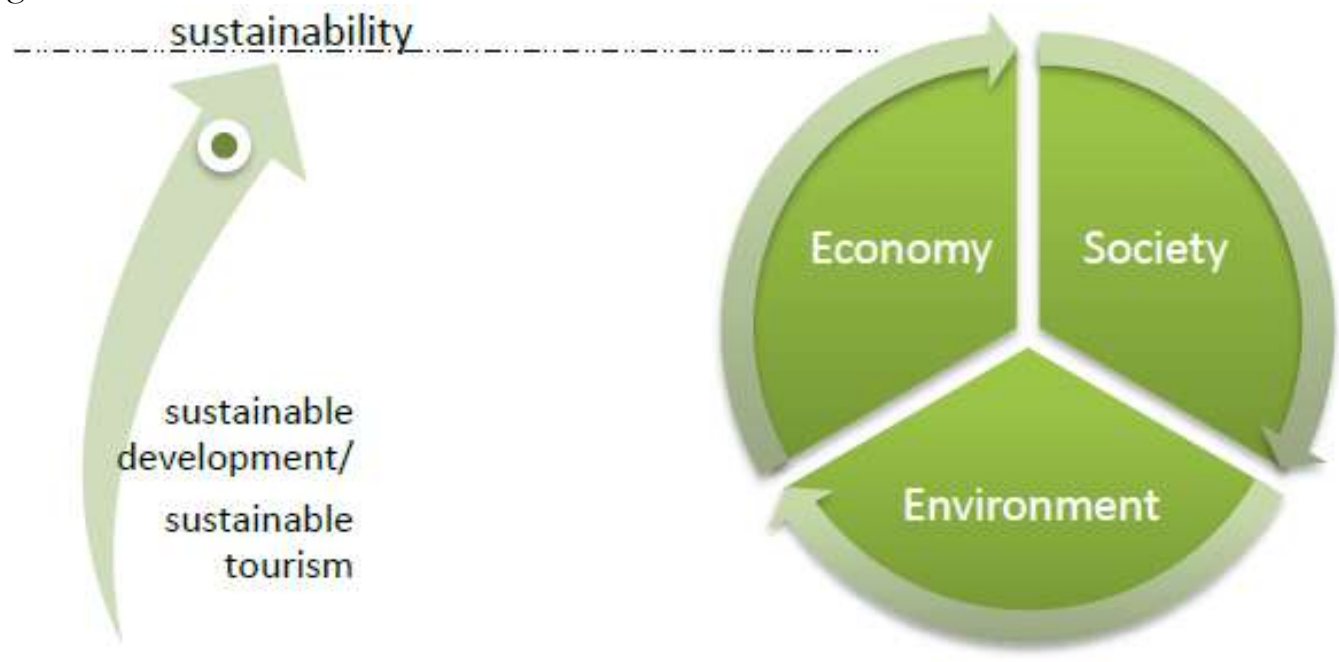

Fig 2 Sustainability

Today, sustainability it is regarded as a desirable intention of tourism development.It embraces the natural environment, the economic situation and the society equally, which is important because these areas influence each other, problems in one area will affect another one. According to Weaver (2006), sustainable tourism can basically be regarded as applying the ideas of sustainable development in the tourism industry. Butler and Harris and Leiper defined sustainable tourism as the forms of tourism that contribute to sustainable development (Lui, 2003). In particular he calls sustainable tourism an adaptive paradigm and not a fixed framework that can be applied to every situation. Sustainable tourism is positive approach intended to reduce the tensions and frictions created by the complex interactions between the tourism industry,visitors, the environment and the communities, it is an approach which involves working for the longterm viability and quality of both natural and human resources. It is not antigrowth, but it acknowledges that there are limits to growth.'(Bramwell \& Lane, 1993)

3. Sustainable tourism practices and tourism sector

The tourism businesses are responsible for waste pollution, increased water and energy consumption in destination areas, creating many(low paid) jobs for local residents ,consumption of product and materials produced by the local economy. As costs for energy, water, etc. are rising, tourism businesses are more or less forced to act economically, environmentally and socially responsible. They have a crucial position in protecting and preserving the environment as they use huge amounts of energy, water and other sources. Nevertheless, sustainable practices implementation do not only help 
to preserve the environment, it helps to reduce costs . Sticking to sustainable practices stands also for the tourism business's "long-term ability to stay in business and be profitable. On the other side, Cavagnaro and Gehrels (2009) argue that tourism enterprises in general are not really aware of sustainability concept. In particular, only few businesses implemented sustainable practices in their daily routines (Bader, 2005). A reason for this could be the unawareness of the public and industry that sustainable practices bring benefits to the surrounding society, economy and environment and of course to them at the same time.

\subsection{Some of the possible reasons why tourism businesses should use sustainable tourism practices}

Growing demand - there is some evidence that a growing portion of visitors is seeking to spend their money on experiences that are sustainable (Uriely, Reichel and Shani, 2007);

Reduces costs - while some sustainability practices require investments in new infrastructure, most do not. By reducing energy or reusing available resources businesses can cut costs considerably.

Differentiates their business from the competition - as markets begin to prioritize sustainable options when purchasing tourism experiences, businesses that are well on the road and publicizing their achievements will differentiate themselves from competitors and stand a greater likelihood to benefit;

Helps attract labour - tourism is a labour intensive industry and attracting and keeping great staff is directly linked to the bottom line. The younger generations are learning about sustainability and are attracted to organizations that are pursuing it.

Adds resiliency to an operation - in an age of volatility, organizations that are more resilient stand a better chance of survival. Many sustainability practices cut costs, put businesses in a stronger market position and establish supply networks and partnerships that help businesses through tight economic periods.

\subsection{Barriers to sustainable tourism practices implementation}

Many studies have identified numerous barriers in sustainable tourism practices implementation (Bohdanowicz, 2006; Graci, 2010; Kasim 2009; Kirkland \& Thompson, 1999). According to Kirkland and Thompton (1999), the barriers may depend on the size of an organization, lack of information,lack of the the necessary resources, its culture and management style. Scarcity of resources may affect the drive to implement sustainable practices; these resources include knowledge, skill, management, staff time, money, equipment and guidance for the environment program (Chan, 2008; Graci, 2010). Kasim (2009) demonstrated that resource constraint is the main factor in many tourism enterprises' nonparticipation in sustainable practices.

Lack of financial resources.

Lack of relevant policies for sustainable tourism development.

Lack of local experts in S.T.Practices.

Lack of incentive programmes 
Lack of education and training.

Lack of guidance from government agencies.

Managers do not have sufficient knowledge.

Lack of support from employees.

Lack of knowledge.

Insufficient physical infrastructure.

Lack of perceived benefits.

The consumer demand is low.

Other priorities

\section{Research methodology}

This study focuses on albanian tourism businessess attitudes toward sustainability as well as the barriers they perceive in implementing sustainable tourism practices. Sustainability and STP are now a reality and albanian tourism businesses can not stay out of this reality. This study was conducted in Korca region during June August 2014 .In order to capture quantitative information about tourism enterprises' awareness of sustainable tourism and STP and how this awareness affected their decision-making, 5-point Likert questions ( $1=$ strongly disagree to $5=$ strongly agree) were used in much of the questionnaire. A total of 80 questionnaires were sent ,but only 67 from them showed their readiness in completing the questionnaire.The questionnaires was sent by e-mail. This procedure resulted in a $83,75 \%$ response rate.

Profile of respodents

Small,medium or large business

\begin{tabular}{|ll|l|l|l|l|}
\hline & & Frequency & Percent & Valid Percent & $\begin{array}{l}\text { Cumulative } \\
\text { Percent }\end{array}$ \\
\hline \multirow{2}{*}{ Valid } & Small & 58 & 86,6 & 86,6 & 86,6 \\
& medium & 9 & 13,4 & 13,4 & 100,0 \\
& Total & 67 & 100,0 & 100,0 & \\
\hline
\end{tabular}

$86,6 \%$ of the respodents are small tourism businesses and $13,4 \%$ are medium ones.

Years of operation in this business

\begin{tabular}{|ll|l|l|l|l|}
\hline & Frequency & Percent & Valid Percent & $\begin{array}{l}\text { Cumulative } \\
\text { Percent }\end{array}$ \\
\hline \multirow{4}{*}{ Valid } & 1-5 years & 26 & 38,8 & 38,8 & 38,8 \\
& 6-10 years & 30 & 44,8 & 44,8 & 83,6 \\
& more than 10 years & 11 & 16,4 & 16,4 & 100,0 \\
Total & 67 & 100,0 & 100,0 & \\
\hline
\end{tabular}

$44,8 \%$ of them have $6-10$ years of operation,followed by $38,8 \%$ with $1-5$ years. This shows that the albanian tourism businesses are new ones, with little experience in this field. 
Number of employees in the business

\begin{tabular}{|ll|l|l|l|l|}
\hline & & Frequency & Percent & Valid Percent & $\begin{array}{l}\text { Cumulative } \\
\text { Percent }\end{array}$ \\
\hline \multirow{4}{*}{ Valid } & $1-5$ & 30 & 44,8 & 44,8 & 44,8 \\
& $6-10$ & 35 & 52,2 & 52,2 & 97,0 \\
& $11-20$ & 2 & 3,0 & 3,0 & 100,0 \\
& Total & 67 & 100,0 & 100,0 & \\
\hline
\end{tabular}

$52,2 \%$ of the respodents have no more than 10 employees.

Implications of research findings

The majority of tourism businesses in the region of Korca are small \& medium businesses therefore it would limit them to invest more in STP.

The main results from the research showed that tourism businesses in Korca region lack of awareness towards sustainability concept. The greatest barrier reported was lack of financial resources. This one both with lack of incentive programmes, other priorities and lack of knowledge are perceived as the most barriers in implementing sustainable tourism practices.

\section{Descriptive Statistics}

\begin{tabular}{|l|l|l|}
\hline & $\mathrm{N}$ & Mean \\
\hline Lack of financial resources & 67 & 4,13 \\
Other priorities & 67 & 3,76 \\
Lack of incentive programs & 67 & 3,72 \\
Lack of knowledge. & 67 & 3,42 \\
Lack of relevant policies for sustainable & 67 & 3,18 \\
tourism development & & \\
Insufficient physical infrastructure & 67 & 3,16 \\
Lack of perceived benefits & 67 & 2,87 \\
Managers do not have sufficient knowledge & 67 & 2,87 \\
Lack of local experts in S.T.Practices & 67 & 2,85 \\
Lack of support from employees & 67 & 2,81 \\
Lack of education and training & 67 & 2,64 \\
The consumer demand is low & 67 & 2,39 \\
Valid N (listwise) & 67 & \\
\hline
\end{tabular}

\section{Conclusions}

The competitiveness of the albanian tourism industry inevitably is closely linked to its sustainability.

A better understanding of tourism enterprise attributes, barriers, and responses is critical if we are to extend the theoretical concepts that underpin sustainable tourism development and to enhance sustainability in practice.

To succeed in making tourism more sustainable it is crucial to work hand in hand with all 
relevant stakeholders.

A sustainable approach to tourism will lead to the development of innovative, quality tourism products- services and make Albania an attractive destination .

The findings clearly show that there is no 'one-fits-all' solution to address the question of sustainability in tourism development by tourism businesses. Should be paid greater attention to the need for sustainability management and its potential benefits.Also putting greater emphasis on sustainability benefits rather than cost savings and regulatory compliance.

\section{References}

Asher, B. (1984). Barriers to International Travel and Tourism. Journal of Travel Research, Vol. 22, No.3, pp. $2-16$

Bansal, P. (2005). Evolving sustainably" A longitudinal study of corporate sustainable development. Strategic Management Journal, 26, 197-218.

Brown, B. J., Hanson, M. E., Liverman, D. M., \& Merideth, R. W. (1987). Global sustainability: Toward definition. Environmental Management, 11(6). 713-719.

Butler, R. (1980). The concept of a tourist area cycle of evolution: Implications for management of resources. Canadian Geographer, 24, 5-12.

Choi, H.C., \& Sirakaya, E. (2005). Measuring Residents' Attitude toward Sustainable Tourism: Development of Sustainable Tourism Attitude Scale. Journal of Travel Research, 43, 380-394.

Cohen, E. (1978). The impact of tourism on the physical environment. Annals of Tourism Research, 5, 215237.

Dyllick, T., \& Hockerts, K. (2002). Beyond the business case for corporate sustainability. Business Strategy and the Environment, 11, 130-141.

Edgell, D.L. (1999). Tourism Policy: The Next Millennium, Vol. 3. USA, Sagamore Publishing

Ehnert, I. (2009). Sustainability and human resources management: reasoning and applications on corporate websites. European Journal International Management, 3(4), 419-438.

Freitag, T. G. (1994). Enclave Tourism Development: for Whom the Benefits Roll? Annals of Tourism Research 21(3), 538-554.

Goodland R., \& Daly, H. (1995). Environmental sustainability: Universal and non-negotiable. Ecological Applications, 6(4), 1002-1017.

Graci, S. (2008). Why go green? The business case for environmental commitment in the Canadian hotel industry. An international Journal of Tourism and Hospitality Research, 19(2), 251-270.

Gössling, S., Peeters, P., Ceron, J.P., Dubois, G., Patterson, T., \& Richardson, R. (2005). The eco-efficiency of tourism. Ecological Economics, 54, 417-434.

Hawken, P. (2007). Blessed unrest: How the largest movement in the world came into

being and why no one saw it coming. New York: Penguin.

Prahalad, C. K. \& Hammond, A. (2002). Serving the world's poor, profitably. Harvard Business Review,September, 48-57.

Sigala, M. \& Leslie, D. (2005). International cultural tourism: management, implications and cases. Oxford: Elsevier Butterworth-Hieinemann

Stipanuk, M. D. (2002). Hospitality Facilities Management and Design. (2nd ed.). Lasing: MI, Education Institute of American Hotel \& Lodging Association.

Zarabi, Asghar, Islami Parikhani, Sadif. (2011). Measure the impact of economic, socio-cultural and environmental impacts of tourism development (case study city meshkinshahr). Research in Human Geography, No. 75, 52-37. 